\title{
CONFLITOS NO USO DA LINGUAGEM NA TECNOMEDIAÇÃO: DIÁLOGOS SOBRE EDUCAÇÃO, ESPAÇO E CULTURA ${ }^{113}$
}

\author{
Marcelo Pessoa ${ }^{114}$
}

\begin{abstract}
RESUMO: Nosso texto apresenta uma breve revisão de problemas históricos da educação brasileira, alinhando a essa discussão, aspectos filosóficos, políticos, culturais e sociais. Após apresentar uma série de questões sobre a educação brasileira, propomos uma estratégia de ensino no ambiente familiar, contexto a partir do qual possamos nos desviar da trajetória aparentemente histórica de fracasso educacional dos últimos cem anos, estabelecendo metas possíveis de se serem alcançadas a partir da discussão da presença maciça da tecnologia no ambiente educacional.
\end{abstract}

PALAVRAS-CHAVE: história da educação, educação ambiental, mediação, sociedade, tecnologia.

\section{INTRODUÇÃO}

As práticas educativas geralmente tendem a fazer parte dos discursos políticos e da pauta de preocupações de primeira ordem de qualquer autoridade pública (particularmente em época de eleições) ou ainda de todo cidadão comum que se apresente à sociedade com o rótulo do "politicamente correto" estampado na face. Isto é, em períodos eleitorais, é bacana falar bem da educação, da segurança, da mobilidade urbana e da saúde pública, e não é bacana falar mal de negros, gays, banqueiros, empreiteiros etc.

A história social e cultural e os bastidores da educação estão verdadeiramente repletos de bons exemplos nesse sentido (de sujeitos inertes, mas, também, de indivíduos reativos e proativos), e há espaço também para aqueles que, como eu, que acreditam que "A educação é

$113 \mathrm{O}$ presente texto é uma síntese de dois momentos de uma mesma pesquisa. O primeiro trabalho, intitulado à época "Educação, Meio Ambiente e Cultura", foi apresentado como resumo no "IX Congresso de Educação Ambiental para o Desenvolvimento Sustentável" da VIII Convenção Internacional sobre Meio Ambiente y Desenvolvimiento, realizada em Havana, Cuba, de 08 a 12 de julho de 2013. O segundo trabalho, derivado do desenvolvimento das pesquisas iniciadas no primeiro texto, foi apresentado como resumo no $62^{\circ}$ Seminário do GEL, em julho de 2014, intitulado "CONFLITOS NO USO DA LINGUAGEM E DO DISCURSO NA TECNOMEDIAÇÃO”, donde, finalmente, chegamos ao formato de artigo completo em 2014, publicado, agora, em 2016.

${ }^{114}$ Doutor em Letras pela UEL (2010), com pós-doutorado em divulgação científica pela USP (2012), Departamento de Zoologia. Docente da UEMG, Unidade Frutal - MG, nos cursos de Direito, Geografia, Administração e Sistemas de Informação. Contato: mpmarcelopessoa@ yahoo.com.br. 
considerada em todos os seus graus como uma função social e um serviço essencialmente público a que o Estado é chamado realizar com a cooperação de todas as instituições sociais" (Manifesto dos Pioneiros da Educação Nova. In: PILETTI \& PILETTI, 2002a, p. 213). Em suma, faço parte do rol dos que ainda acreditam na educação como emancipadora de consciência, e não como reprodutora cataléptica de postulados.

A Escola, sob o ponto de vista de um marxismo tardio (que enxerga a Escola como principal ingrediente emancipador do homem) é uma destas instituições que, ao lado de outras como a Família, a Igreja, o Exército, o Estado, atraem para si a responsabilidade de gerir os protocolos da boa intenção individual e coletiva quanto aos rumos da sociedade como um todo.

Mas, como o foco de meu ataque é a academia, perguntamo-nos muito sobre ela, a Universidade: o que e como, de fato, a Escola Superior faz para ensinar determinados conteúdos? O que realmente podemos informar aos indivíduos bem intencionados de nossa sociedade quanto ao status quo da ensinança superior no Brasil, após quase um século de história de ensino universitário brasileiro ${ }^{115}$. O que podemos dizer sobre as práticas educativas reais que acontecem nas salas de aula? Será que o Estado atendeu ou decepcionou ao cidadão quanto ao atendimento das demandas postas em pauta pelos "pioneiros" do escolanovismo dispostas em seu manifesto de 1932? A nossa sociedade, enfim, conseguiu ou está apta para atingir quaisquer das metas educacionais expressas nos moldes do que se relata pela UNESCO, a seguir?

Aumentar o acesso tornou-se uma prioridade para a maioria dos Estados Membros e as crescentes taxas de participação na educação superior são uma tendência global ainda maior. Porém, grandes disparidades ainda persistem e constituem uma fonte maior de desigualdade. Governos e instituições devem estimular o acesso, a participação e o sucesso das mulheres em níveis de educação. Em acesso crescente, o ensino superior deve buscar as metas de igualdade, relevância e qualidade, simultaneamente. Igualdade não é simplesmente uma questão de acesso o objetivo deve ser a participação e a conclusão efetiva, enquanto o estudante recebe um auxílio. Este auxílio deve incluir suporte financeiro e educacional adequados para aqueles que vivem em comunidades pobres e/ou marginalizadas (UNESCO, 2009, p. 247).

115 O ensino superior passou por importantes modificações a partir de 1930. Com a criação das primeiras universidades, superou-se a fase das escolas superiores isoladas, de caráter marcadamente profissional. A criação da Universidade de São Paulo, em 1934, tornou-se possível graças aos Estatutos das Universidades Brasileiras (Decreto no 19.851, de 14 de abril de 1931). Atendia-se, dessa forma, às reivindicações dos educadores que, principalmente a partir da década anterior, vinham insistindo na necessidade de se instituir o ensino universitário (PILETTI \& PILETTI, 2002a, p. 211). 
Não desconhecemos os esforços governamentais no estabelecimento de ações afirmativas para promover o incremento ao acesso e a fixação do discente na Universidade. A Lei de Cotas, o Reuni, o Prouni, o FIES são exemplos dessas ações. Contudo, nosso pensar e nosso falar por aqui, portanto, não é o de questionar os vícios ou as virtudes do sistema ou a contundência evidente das estatísticas de evasão ou de retenção no ensino superior, mas dizer que, apesar disso tudo:

A evasão de estudantes é um fenômeno complexo, comum às instituições universitárias no mundo contemporâneo. Nos últimos anos, esse tema tem sido objeto de alguns estudos e análises, especialmente nos países do primeiro mundo, e têm demonstrado não só a universalidade do fenômeno como a relativa homogeneidade de seu comportamento em determinadas áreas do saber, apesar das diferenças entre as instituições de ensino e das peculiaridades sócio-econômico-culturais de cada país (VELOSO, 2000, p. 14).

Em 2001 (dados do IBGE, computados entre 2001 e 2009), tivemos 15 milhões de estudantes ingressantes no ensino superior, o que não quer dizer muito, se vermos que entre 2001 e 2009 , houve uma escalada de evasão ou de retenção de discentes que não se formam nesta mesma faixa de ensino, na média de $40 \%$ ou $50 \%$.

Indiscutivelmente os números que medem o contingente de ingressantes no sistema elevam nosso IDH (índice de desenvolvimento humano) e também transformam o nosso povo predominantemente semiletrado em intelectuais esplêndidos. Após quatro anos morando nos Estados Unidos, o outrora unânime e hoje controverso Monteiro Lobato, escreveu, em 1927, sobre a possibilidade de voltar a viver no Brasil:

Eu, por mim, não sairia mais daqui, porque o Brasil torna-se grotesco visto de longe. Infelizmente, a família é um cordão umbilical que me prende a essa cataplasma. Só agora meço em extensão o atraso, e a estupidez maior ainda, da nossa gente. Somos África pura (Monteiro Lobato. In: SODRÉ \& PAIVA, 2002, p. 15).

Igualmente, nem de longe vamos tocar no delicado assunto da valorização econômica do profissional da educação, já que no ano de 2012 assistimos uma das maiores paralisações da história do funcionalismo público federal e também dos profissionais do ensino público superior no país, protagonizada em massa pelas universidades federais e por algumas instituições estaduais isoladas:

No caso dos professores, inicialmente, nos tempos da educação jesuítica (período colonial), eles eram valorizados como trabalhadores intelectuais, na medida em que detinham todo o saber sistematizado veiculado na Colônia. Após a expulsão dos jesuítas do país, em 1759, surge, em 1772, uma 
"política de oferta direta da instrução gratuita através de professores assalariados" (MONLEVADE, 2001, p. 23) 116: os professores das "aulas régias" ou professores de disciplinas específicas, improvisados e mal pagos. Tem-se, assim, uma desvalorização do trabalho docente: de trabalhadores intelectuais, esses "profissionais" passam à condição de intelectuais trabalhadores, que recebem um "salário" (precário) pago pelo seu trabalho (MEC, 2006, p. 17).

Não tocaremos em tais assuntos, não por que não sejam relevantes, mas por que estas são, ou pelo menos deveriam ser, questões sine qua non para o exercício docente e jamais deveriam sequer aparecer como "problema" numa pauta de discussão tão despretensiosa como a que realizo aqui.

Vamos, por hora, apenas propor horizontes para refletirmos sobre a transmissão de conteúdos, a natureza desta ou daquela disciplina. Enfim, não iremos, a partir deste texto, restaurar nada e nem descascar feridas ou reabrir cicatrizes. Apenas faremos sugestões e, quando muito, poucas considerações modestas sobre a área da Educação.

\section{Desenvolvimento: contexto e fundamentos do problema}

A problematização educacional e, consequentemente, das informações sobre o assunto, é mais que uma preocupação social, política, filosófica, é uma questão ainda de formação, de base, e se constitui, sobretudo, num tipo de estratégia de transmissão de conhecimentos.

$\mathrm{Na}$ "pré-história" de uma disciplina transversal em muitos currículos, por exemplo, como é o caso da disciplina de Educação Ambiental, vê-se que a ciência geral total sobre o assunto começa com as observações da natureza, abordada sob estes dois extremos (suas especificidades e suas generalidades) e, depois é que se parte para o estudo da presença e da intervenção do homem no meio ambiente:

Especialmente a partir das décadas de 1970 e 1980, os historiadores vêm contribuindo para a compreensão dos dilemas ambientais que o mundo contemporâneo enfrenta. Essa contribuição específica da história recebe, muitas vezes, o nome de história ambiental. Consolidada nos Estados Unidos e na Europa, a história ambiental ainda está mal instalada no Brasil, já que não adquiriu, até agora, maior legitimidade entre historiadores e cientistas sociais. Talvez algumas disciplinas julguem existir questões mais urgentes, como as do desenvolvimento econômico, da extrema desigualdade social, dos revezes da democratização (MARTINS, 2008, p. 69-70).

${ }^{116}$ A referência à qual o texto alude é: MONLEVADE, João. 13 lições sobre fazer-se educador no Brasil. Brasília: Idea Editora, 2001 (In: MEC, 2006). 
Por isso, lembro que contemporaneamente, iniciou-se uma convergência de esforços sobre o assunto, a partir da publicação da obra Primavera Silenciosa (1962), de Rachel Carson, e da realização da "Conferência das Nações Unidas sobre o Meio Ambiente Humano”, na cidade de Estocolmo (Suécia), em 1972. De lá para cá, vimos que não foi mais possível se falar sobre o papel do homem sem considerá-lo um ente à parte do meio ambiente, e o inverso também é verdadeiro:

Segundo Georges Gusdorf (1970), a história natural constitui uma nova aliança entre o homem e a natureza, um novo contrato de permanência do homem no mundo. Na verdade, o homem não está ausente da história natural; antes, tem seu lugar na "grande cadeia dos seres". Se ele reina no topo da ordem natural, o homem faz parte dela, dado que, conforme Linné, na décima edição do Systema Naturae (1758-1759), "ele é um animal mamífero", pertencente à ordem dos primatas. De acordo com a tradição cristã, a natureza é feita para o uso do homem. Mas este, que é a única criatura capaz de venerar Deus, também deve ser o mantenedor das proporções instituídas por aquele que Linné chama de "o Supremo moderador" (VIVIEN, 2011, p. 37).

Compreender in loco o que e o como que o sujeito social age no meio ambiente pode ajudar a perceber como o sujeito histórico atua na realidade, uma vez que ambos (sujeitos social e histórico) tendem a ver a natureza como um "outro", um ser à parte, e não como meio em que todos vivem mantendo uma relação de interdependência.

Nesse sentido, acredito muito no que nos ensina o filósofo Mário Sergio Cortella. Diz-nos ele, mais ou menos nestes termos: "mais do que nos preocuparmos com o mundo que nós vamos deixar para os nossos filhos, precisamos nos precaver é quanto aos filhos que nós deixaremos para o mundo".

E essa preocupação se legitima, pois, numa observação da recente história da educação, vê-se nela certo desajuste em sua função emancipadora, devido à predominância de uma ideia de educação reprodutora. Isto é, o aporte educativo disponibilizado ao consumidor final parece sempre estar contaminado pela semântica da alienação, uma vez que eivado de expressões-clichê e de irrelevâncias conceituais que parasitam ao seu redor, sugando de si sua essência transformadora.

Sob o rótulo de uma distribuição em massa de informações, se pratica, então, uma modalidade de educação adjetivada de "tecnológica", a qual, por vício de origem, já nasceria contaminada de palavras e de abordagens fadadas ao fracasso. Estas abordagens ou expressões são visíveis em frases como "ensino a distância", ou "estudo quando, onde e como puder", ou "seja você mesmo o responsável pela evolução e aquisição do conhecimento" e assim por diante.

Por isso é que na atualidade, pensamentos como o da precarização do trabalho docente, do reposicionamento discente, da participação da família na Escola etc., e da força econômica do segmento educacional, são temas que ganham espaço na mídia e caem no gosto popular, ainda que poucos sejam aqueles que 
dentre o povo entendam desse assunto ou realmente se dediquem de fato a "estudar", já que muitos são os alunos, mas poucos são os estudantes.

Nesse cenário, sem incorrer em reducionismos, sabemos pela observação empírica, que práticas de educação em qualquer disciplina conduzidas por esses vieses, normalmente se perdem no território do politicamente correto e, finalmente, caem no esquecimento e dormem sossegadas embaladas pelos jingles das sedutoras e entorpecentes propagandas eleitorais.

Por mais bem intencionadas que sejam as propostas educativas formuladas e motivadas a partir de tais premissas, o desajuste entre ideal e real na área da Educação ainda persiste, uma vez que é praticamente inevitável o confronto delas com questões relacionadas à eficiência aplicada e análise dos resultados objetivos. Como se nota, por exemplo, na questão ambiental, fala-se sempre que o planeta está cada vez mais "precisando ser salvo", mas do quê exatamente? Talvez, da falta de autodeterminação do ser humano em mudar a si próprio:

Desde o século XVI, a natureza é comercializada como uma mercadoria das mais lucrativas. Vender e comprar a natureza. Qual é o preço da vida? A cultura do consumo fabricou valores comerciais compatíveis com o desenvolvimento de mercados internacionais. Muito se ganhou, mas nada em comparação com as perdas culturais e ambientais. Muito do que se conhece, do que se procura compreender e combater na contemporaneidade, é decorrência e extensão dos movimentos mercantis do passado (BARCELLOS, 2008, p. 109).

Todas estas ponderações podem dar origem a soluções igualmente válidas à problemática educacional, à questão socioambiental, especialmente em se tratando de educação infantil, em sentido lato, ou de educação ou de informação para adultos, em sentido stricto. Desse modo, atrevemo-nos a lançar na sequência uma sugestão revisionista, ainda que as questões-problema da educação e de seu entorno coligadas sejam significativas e muito atraentes, nosso paper trata, em última análise, de fatos relativos ao território da mediação no ensino e, especificamente, sobre o modo de transmissão de conteúdos em ambientes tradicionais de ensino e dos mais tecnológicos.

\section{Transmissão de conteúdos: perspectivas e sugestões}

Para dinamizarmos o foco de nosso breve debate neste fórum sobre conteúdos e os seus modos de transmissão, podemos estabelecer dois fronts básicos que são aparentemente paradoxais no processo de ensino-aprendizagem.

De um lado de nossa exposição do processo de ensinar e aprender vê-se que a Escola trabalha seus conteúdos, ou pelo menos deveria trabalhar sob a ótica de 
uma Escola emancipadora, com o propósito de formar cidadãos críticos e transformadores para a sociedade:

Uma das maiores preocupações dos educadores é, sem dúvida, o desenvolvimento intelectual dos alunos, visando à autonomia de pensamento, à facilidade de elaboração e expressão de ideias e à formação do pensamento crítico. Mas, a escola, não tem tido muito êxito neste aspecto e, sem dúvida, isto se deve, em grande parte, à maneira: como o processo ensino-aprendizagem é conduzido (VALENTE, 2007, p. 263).

E, de outro lado, que a assim denominada "academia", por alguma razão, fracassa em seus propósitos basilares, já que movimenta suas ferramentas do conhecimento no sentido de construir um tipo de sujeito, ao invés de sábio, cada vez mais "adestrado" e apto a se conformar com o establishment, com o status quo e com todas as demais categorias socioculturais do gênero cooptação em tais contextos cabíveis.

A razão de isso ser assim supomos que resida tanto em fatores pontuais, como a episódios de certo desinteresse do estudante pelo aprendizado ("É muito pouco provável a ocorrência de aprendizagem quando o aluno na tem interesse em aprender", VALENTE, 2007 , p. 281), quanto em fatores conjunturais, como as intervenções desastrosas do Estado no contexto da educação:

A reforma de 68, a partir da pressão dos movimentos estudantis e de professores, sob a tutela do Estado, mas que não contou com a presença de seus elementos mais críticos e criativos que haviam sido afastados pelo regime militar, levou à intensa centralização, estabeleceu mecanismos de controle burocráticos, excluindo os docentes dos centros de decisão, levando-os a perder a visão de conjunto da instituição e reforçando o isolamento das unidades acadêmicas (SARMENTO, 1991; MORAES, 1999, In: PEREIRA, 2003, p. 30).

Essa macroestrutura é idealizada, perniciosa e de dupla dissociação do ensino em relação aos seus gestores e de dissociação do ensino com a tomada de consciência sociocultural. Assim, atingiu em certos momentos, picos de intensidade tão elevados que, em alguns teóricos do sistema educacional, chegou-se mesmo a propor uma desescolarização, isto é, um fim da escola face à distância da realidade que dentro dela se constrói:

A teoria da desescolarização constituiu uma posição extremista e até reacionária em relação à escola. Seu principal representante, o já falecido Ivan Illich, foi por muitos anos Vice-reitor da Universidade Católica de Ponce, Porto Rico, e fundador do Centro de Estudos sobre educação em Cuernavaca (México), em 1963. Seus trabalhos foram amplamente lidos na América Latina, especialmente na década de setenta. Em sua obra mais importante, Uma Sociedade sem Escolas (1973), I. Illich passa a engrossar o 
mar de acusações à escola oficial, e sua proposta teve resultados interessantes para aqueles que desejavam desmistificar o discurso oficial dos intelectuais orgânicos do Estado capitalista (PUENTES, 2004, p. 48).

Difícil sabermos em qual dos dois polos nos encontramos (formamos cidadãos críticos ou alienados? - talvez assim se perguntasse Foucault ao ler esta nossa exposição). O sistema de ensino superior está contaminado de uma produtividade praticamente fordista. Alunos saem hoje das universidades como se estivessem numa linha de montagem. Professores não atuam como seres humanos autônomos, mas como gerentes e braços alongados do "dono", isto é, são hoje não mais que capatazes brandindo seu chicote acadêmico, vociferando a hegemonia de um conhecimento que se reconhece falido ao se legitimar pelo uso das próprias irrisões que contesta.

Nosso aparato educacional hoje em operação não faz muito mais do que adestrar nossos estudantes. Devidamente adestrados pela ditadura quantitativa da produção científica, nós, os professores, impedidos ou sem tempo para pensar, adestramos nossos jovens para "passarem de ano", enquanto isso, num nível acima, os adestramos para "passarem no vestibular" e, num rigor de crueldade do processo, uma vez na universidade, os adestramos "para obterem êxito no ENADE" e demais exames de proficiência profissional "OAB, CREA, CREF etc." e, finalmente, "para se saírem bem no mercado de trabalho" e, inevitavelmente, este contexto tem encontro marcado com o pensamento de Michel Foucault, quando este nos diz que a Educação contemporânea é uma espécie de ópio de nossa civilização.

\section{Discussões}

Após estes primeiros alinhavos, numa visão panorâmica hipotética sobre a Educação, podemos estratificar basicamente dois níveis de preocupação quanto à reprodução e a emancipação.

O primeiro é o nível conservacionista. Nesse patamar se requer dos agentes socioculturais uma atitude passiva diante das condições e fenômenos naturais presentes no sistema educativo, aos quais voluntária ou involuntariamente o sujeito se expõe.

Nesse nível praticamente não se exige do sujeito social e histórico qualquer atitude que viabilize uma convivência harmônica com o sistema e seus recursos. O homem, sob a batuta de uma orientação educacional conservacionista, para não repetirmos trechos de nossa fala anterior e dizermos que se torna um "adestrado educacional", diremos que se torna um alienado. Assim, ele é praticamente um "síndico de massa falida" ou, nos termos jurídicos mais atualizados sobre este assunto, um "administrador judicial" 117 .

117 Estas terminologias jurídicas e suas respectivas funcionalidades estão previstas e descritas, de um lado, no antigo Decreto 7661/45 - Síndico de Massa Falida, revistas pela Lei 11.101/05 - Administrador Judicial. 
Isto é, é alienado na medida em que ele tem a posse do bem (o conteúdo), mas não a propriedade. Noutros termos, ele, apesar de não ser o "dono do conhecimento" deve agir responsavelmente na guarda dos conteúdos com os quais interage, ainda que não possa ou não queira atuar de modo a modificá-lo (positiva ou negativamente).

Valendo-nos de outra figura do meio jurídico, lembramos que esse "administrador educacional" não pode ser confundido com a figura jurídica do fiel depositário, uma vez que este último, normalmente, em condições reais de falência empresarial, é o próprio falido. Ou seja, numa prática conservacionista de "administração / conscientização educacional" a nossa mente tende a acreditar que nós não somos o sujeito social educacionalmente "falido" - já que somos apenas os administradores do problema e não os fiéis depositários. Por isso, temos a convicção de que o ônus desse tributo deve recair sempre sobre "outro" sujeito social que não aquele que o administra.

Este "gestor de consciência educacional" que nós estamos aprendendo a ser a partir do tipo de Educação que temos predominantemente acesso, por sua vez, pensa, assim, serem sempre "os outros" os culpados pelos descasos praticados no setor.

No meio jurídico, no rol de compreensão das figuras do "administrador judicial" e do "fiel depositário" é assim mesmo que funciona também. O administrador judicial nunca pode ser a mesma pessoa que o falido - há um impedimento legal para isso -, e, numa visão de um terceiro participante, este "gestor de consciência educacional" nunca coloca a si próprio como parte do problema.

Talvez, no nível do discurso, isso aconteça, mas, na prática, parece faltar algo para que se passe do discurso à realização. Consequentemente, este sujeito social que deveria ser a chave para a solução da questão, agrava ainda mais a situação, uma vez que vive alienado de sua própria condição.

O resultado disso, é que, se aprendemos a pensar a Educação partindo de uma ótica assim terceirizada, que nos ensina que o educacionalmente falido sempre será o "outro", provavelmente Sergio Cortella tenha razão e, parafraseando-o, perguntamo-nos: que ensinamentos sobre cidadania emancipatória estamos repassando para os nossos alunos?

O segundo nível da conscientização educacional é o da conformidade. A sociedade, mais especialmente, a tecnologia por ela produzida, se conforma, isto é, se adéqua ao meio, não necessariamente aceitando passivamente as condições do sistema como no primeiro nível, mas buscando tirar das circunstâncias educacionais o melhor resultado possível.

De pronto, vemos que esta postura, a da conformidade, já difere da maneira conservacionista. Na mesma linha da alegoria jurídica anteriormente empregada, observa-se que o sujeito social que atuar no território do ensino-aprendizagem no nível da conformidade, sairá da esfera passiva em que transita aquela, a da 
consciência do "administrador educacional", e se deslocará para o território do "fiel depositário" educacional118.

Ele passa a se preocupar com a manutenção e conservação do patrimônio sob sua tutela. Insere em sua pauta comportamental a necessidade de se desenvolver estratégias de convivência harmônica com os outros integrantes do sistema.

Taticamente, esse projeto de Educação se alinharia ao perfil de ensino necessário para realizarmos a revisão de nosso maior produto social e cultural - 0 Homem. Isto é, estaríamos cuidando, assim, de melhorar a qualidade dos filhos que nós estamos deixando para este mundo. Mas, para se conseguirmos avanços efetivos nessa área, teríamos de promover um tipo de Educação personalizada?

\subsection{Uma escola da conformidade ou escola da mediação?}

Para sairmos de uma prática conservacionista e entrarmos numa prática de conformidade, seria necessário que se criassem grupos de educadores que atuassem como os "médicos de família" do passado. Ou seja, haveria, para um grupo de 20 famílias, por exemplo, um ou dois educadores (pagos pelo Estado ou pela iniciativa privada, não importa, por hora) responsáveis pela orientação, pela construção do sujeito histórico, que seriam responsáveis pela desalienação sociocultural de todos naquelas casas em que visitasse.

Essa prática, exercida por meio de visitas semanais durante todo o ano letivo permitiria que se recuperasse dos armazéns do inconsciente coletivo aquela atividade de educação outrora enobrecedora do educador e do educando, promovendo-se o que Nelson Valente (2007, p. 263), mais atrás em nosso texto, nos disse como sendo verdadeiramente o real papel do professor: "o desenvolvimento intelectual dos alunos, visando à autonomia de pensamento, à facilidade de elaboração e expressão de ideias e à formação do pensamento crítico", ou ainda ele próprio salienta sobre os pilares da paidea da antiguidade grega:

A Grécia Clássica pode ser considerada o berço da pedagogia. A palavra paidagogos significa aquele que conduz a criança, no caso, o escravo que acompanha a criança à escola. Com o tempo, o sentido se amplia para designar toda a teoria da educação. De modo geral, a educação grega está

118 Carlos Henrique Bezerra Leite (2006, p. 851), aponta algumas características e o principal objetivo do depósito dentro do processo: "O objetivo do depósito reside na manutenção e na conservação dos bens penhorados, de modo que propicie a plena realização da finalidade do processo de execução. O depositário pode ser público ou particular. Em ambos os casos será sempre um auxiliar da justiça, exercendo, pois, função de caráter público. Embora não haja vedação legal, não é recomendável que a nomeação de depositário recaia em empregado do executado, mormente quando este for ocupante de cargo ou função hierarquicamente inferior na empresa, tendo em vista a sua condição de vulnerabilidade perante o empregado", texto disponível

em http://www.lfg.com.br/public html/article.php?story=20110725162855988\&mode=print, acesso em $23 / 08 / 2012$, às 15 h40min. 
constantemente centrada na formação integral - corpo e espírito - mesmo que, de fato, a ênfase se deslocasse ora mais para o preparo esportivo ora para o debate intelectual, conforme a época e lugar (VALENTE, 2007, p. 159).

Esse educador de família acompanharia os pais, não só, mas, especialmente os filhos que nascessem num certo lar. Veria o crescimento dessas crianças, orientando, indicando melhores condutas sociais, auxiliando na composição da pauta cultural, seria quase um tutor.

Conseguimos, de certo modo, até imaginar o quanto isso também não contribuiria para uma revalorização social e cultural dos professores envolvidos numa prática educativa assim constituída.

Ensinar no nível da conformidade, portanto, não é o mesmo que ensinar para ser conformado. Conformidade é o desenvolvimento de saberes para a adequação, conformismo é a aceitação da cooptação e do treinamento contínuo e massivo para a sujeição passiva aos processos socioculturais.

Qual o resultado de tudo isso? Óbvio! Interromperíamos a reprodução incessante de sujeitos sociais domesticados e sujeitos históricos alienados.

Como esperar, portanto, que alienados domésticos passem, de repente, a se preocupar com questões muito abstratas, como, por exemplo, a ideia de uma obra de arte, do cinema como metáfora social, ou a de que o mundo pode colapsar e a natureza, nalgum tempo futuro, poderá repentinamente se rebelar contra todos nós?

\section{Como concluir algo que não tem fim?}

Se considerarmos que dentro do conceito de aprendizagem, um de seus princípios fundadores é o de que a aprendizagem efetivamente só acontece quando se expõe o indivíduo ao conhecimento, teremos o grau máximo de eficácia das estratégias de educação num nível de conformidade quando conseguirmos aproximar ilimitadamente o educando daquele tipo de conteúdo que se deseja que ele deva dominar.

Assim, a exemplo contrário disso, é o que ocorre hoje com a internet. Esta que, talvez, seja a principal das TICs (tecnologias de informação e comunicação), certamente é o veículo por meio do qual as redes sociais e os sites de busca de conteúdos predominantemente se desenvolvem, sedimentando paulatinamente uma crença coletiva de que as TICs, então, constituem-se numa realidade tão inevitável quanto imprescindível à produção e à difusão do conhecimento.

Contudo, ao aceitarmos esse contexto como território de exercício da unanimidade em torno da relevância inconteste das TICs, indiretamente hasteamos uma bandeira sociocultural que legitima o uso cada vez mais frequente e indiscriminado destas mesmas TICS nos mais diversos setores da sociedade (segurança, saúde, trocas comerciais, reprodução de bens culturais como a 
linguagem, relações diplomáticas, e, por conseguinte, a educação), condição esta que passou a oferecer aos cientistas da tecnologia, da sociedade e, especialmente, dos usos e suportes da linguagem e da educação, novos horizontes de pesquisa.

Para entendermos esta dinâmica na Educação, teremos de recombinar o DNA da "velha" Educação com o da "nova" Educação. Retirar desta ou daquela modalidade lentamente os genes da prática conservacionista e inserir, paulatinamente, os fragmentos da educação nos moldes da conformidade, escola por escola, governo por governo.

Ensinar a pensar é sempre mais difícil? Sim. Mas, essa não seria mais uma expressão-clichê que mora ao lado daquelas que repudiamos no início de nosso texto? Também é. Portanto, saiamos igualmente das amarras dessas palavras, e imaginemos que mais difícil ainda talvez seja "pensar para ensinar".

Pensar o processo histórico de ensino-aprendizagem é sempre importante. Mas, refletir e propor novas possibilidades e abordagens talvez nos apresente novos caminhos a seguir sobre a Educação, sobre o meio ambiente, sobre nossa gente, enfim, e que não seja o de tom pejorativo relacionado à "África pura", como nos houvera sugerido Monteiro Lobato.

Em nosso caso, repensar a Educação sob a ótica de terminologias jurídicas ou de velhas práticas educacionais como a da Paideia é o foco onde reside nossa parcela de contribuição para um tipo de desenvolvimento humano que se entenda ético e socialmente transformador.

A educação familiar, finalmente, não é e nem tem a pretensão de ser a "salvação da Pátria munida de giz nas mãos": ela é, além disso, o que desejaríamos que fosse a própria Educação.

\section{REFERÊNCIAS BIBLIOGRÁFICAS}

BARCELLOS, Gilsa Helena. A Crise Ambiental e a Mercantilização da Natureza. In: HISSA, Cássio Eduardo Viana. Saberes Ambientais. Belo Horizonte: UFMG, 2008, p. 109-123.

MARTINS, Marcos Lobato. História e Meio Ambiente. In: HISSA, Cássio Eduardo Viana. Saberes Ambientais. Belo Horizonte: UFMG, 2008, p. 65-77.

MEC - Ministério da Educação. Secretaria de Educação Básica - Conselho Escolar e a valorização dos trabalhadores em educação. Brasília - DF, 2006. Disponível em http://portal.mec.gov.br/seb/arquivos/pdf/Consescol/cad\%208.pdf.

INEP - Instituto Nacional de Estudos e Pesquisas Educacionais Anísio Teixeira. Censo da Educação Superior 2010 - Resumo Técnico. Disponível em http://download.inep.gov.br/educacao_superior/censo_superior/resumo_tecnico/resumo tecnico_censo_educacao_superior_2010.pdf. 
PEREIRA, Fernanda Cristina Barbosa. Determinantes da evasão de alunos e os custos ocultos para as instituições de ensino superior: uma aplicação na universidade do extremo sul catarinense. UFSC: Florianópolis, 2003 (tese de doutorado).

PILETTI, Claudino \& PILETTI, Nelson. Filosofia e História da Educação. São Paulo: Ática, 2002a.

PILETTI, Claudino \& PILETTI, Nelson. História da Educação. São Paulo: Ática, 2002b.

PUENTES, Roberto Valdés. Os Estudos da Teorias Educativas na América Latina. São Paulo: UNIFEOB, 2004.

SILVA, Roberto Marinho Alves da. Entre o Combate à Seca e a Convivência com o Semi-árido - transições paradigmáticas e sustentabilidade do desenvolvimento. Fortaleza: Banco do Nordeste do Brasil, 2010.

SODRÉ, Muniz \& PAIVA, Raquel. O Império do Grotesco. Rio de Janeiro: MAUAD, 2002.

UNESCO. As Novas Dinâmicas do Ensino Superior e Pesquisas para a Mudança e o Desenvolvimento Social. Conferência Mundial sobre o Ensino Superior. Paris, França, 08 de julho de 2009.

VALENTE, Nelson. Não Adapte. Adote. São Paulo: Intermedial, 2007.

VELOSO, Thereza Cristina M. A. A Evasão nos Cursos de Graduação da Universidade Federal de Mato Grosso, Campus Universitário de Cuiabá 1985/2 a 1995/2 - Um processo de Exclusão. UFMT: Cuiabá, 2000 (dissertação de mestrado). In: PEREIRA, Fernanda Cristina Barbosa. Determinantes da evasão de alunos e os custos ocultos para as instituições de ensino superior: uma aplicação na universidade do extremo sul catarinense. UFSC: Florianópolis, 2003 (tese de doutorado).

VIVIEN, Franck-Dominique. Eco - nomia e logia. São Paulo: SENAC, 2011. 